\title{
The Cultivation of Practical Ability of College Students in Basic Computer Courses
}

\author{
Yiliu Yang \\ Research and Teaching Institute of College Basics, Bohai University, Jinzhou City, Liaoning Province, \\ 121013, China
}

Keywords: College, Practical ability, Computer foundation, Curriculum reform

\begin{abstract}
Under the new normal economy, the whole society has a greater demand for computer professionals. In this context, in the teaching of basic computer courses, students should not only grasp the basic knowledge, but also implement the guiding principle of ability cultivation. According to the teaching goal and the demand of the whole society to the professional talents' comprehensive skill, the teaching reform is promoted. In view of how to improve the students' practical ability of computer foundation, this paper put forward the reform countermeasures of college basic computer course teaching. The author first analyzed the teaching reform's goal of the basic course of university computer, and then put forward the main ideas of the teaching reform in the basic course of university computer. Moreover, the main ideas of the reform include the establishment of core curriculum, the development of three-dimensional teaching materials, the reform of curriculum teaching, the construction of experimental teaching system, the application of multiple teaching models, the construction of information resources and learning platforms.
\end{abstract}

\section{The Teaching Reform Goal of the Basic Course of University Computer}

The basic course of university computer undertakes the important task of cultivating students' computer ability. Computer competence is the ability of a student to use information technology to solve problems in a professional field. Computer competence consists of three levels: The first level is the ability to operate, which is the basic skills of students skilled in the use of computers; the second level is the comprehensive application and design ability. It is the professional ability to solve the professional field problems by using the computer. The third level is the innovation ability, which is the further expansion of the first two abilities. In order to cultivate students' computer ability, it is necessary to change the teaching of basic computer course from "knowledge imparting to guidance" to "ability cultivation", and to use diversified teaching mode. On the basis of knowledge imparting and skill training, more attention should be paid to the cultivation of students' information quality and problem-solving ability. We should permeate the ability training into the course education of the whole subject and improve the quality of education and teaching in an all-round way. Based on this, the aim of the teaching reform of the basic course of university computer is to take the computer knowledge as the carrier, to cultivate the ability as the guidance, and to use the diversified teaching mode ${ }^{[1]}$. In order to cultivate students' information literacy and computer application ability, non-computer major students should be educated in knowledge, ability and quality based on computer.

\section{Reform Ideas on University Basic Computer Course Teaching}

\subsection{Establishment of Core Curriculum}

With the aim and guidance of cultivating students' computer ability, the core curriculum should be established scientifically to create conditions for students to learn and improve their comprehensive ability. According to the requirements of computer basic teaching and the goal of talent training, the core courses include seven courses of database technology, programming of Visual Basic, programming of web pages and computer aided design. Computer network technology, 
multimedia application technology, involving system platform, program design, data management, information processing and so on. In addition, each course includes concepts and foundations, techniques and methods, and the application of professional knowledge in three fields. Through the reasonable determination of these teaching contents, it is better to guide the basic computer course teaching, and also to improve the students' computer ability ${ }^{[2]}$.

\subsection{Development of Stereoscopic Teaching Materials}

In order to create conditions for the improvement of students' computer ability, we should change the way of using paper teaching materials separately, adopt the "four-in-one" stereoscopic teaching materials, and pay attention to the renewal of teaching contents in order to improve the students' computer ability. First, we use paper teaching materials to improve students' computer skills, and use heuristic case teaching methods. According to the reasonable preparation of paper teaching materials according to the syllabus, we improve the science and rationality of the teaching materials, so that students can effectively improve the comprehensive ability of computer after learning. The contents of each chapter should be arranged rationally, and the contents of each chapter should be introduced by new items, problem solving and case analysis, so as to stimulate students' interest, to better integrate them into learning activities and to improve their comprehensive computer skills. Second, online learning activities make use of computer network to provide learning resources for students to choose independently and carry out knowledge development and extracurricular training. In the ideal digital environment, we should deepen the understanding of the basic knowledge of the computer, and then improve the comprehensive ability of the computer. Third, the learning auxiliary CD mainly includes the key point explanation, the reading development, the unit test and so on. We should set up the auxiliary optical disc in combination with the contents of the teaching materials, explain and analyze the knowledge points, and facilitate the students to understand and accept. Students can learn independently after class, so that to break through the key points and difficulties. Fourth, the experiment practice system takes improving the computer application ability as the core; we should perfect the experiment practice system setting up, so that to establish the computer skill knowledge exercise database. In teaching, test and experiment are combined to guide students to carry out practical activities by using task-driven way, so that students can explore independently, deepen their understanding of what they have learned, and improve their ability to apply computer knowledge.

\subsection{Reform of Curriculum Teaching}

The aim of improving students' comprehensive ability of computer is to promote the reform of curriculum teaching, and to pay attention to the application of new teaching methods and improve the examination methods. First, the new teaching method adopts the teaching mode of "instructing + tutoring + independent learning + computer proficiency test", which provides abundant teaching resources for students. The 10 hours of classroom instruction and 10 hours of computer practice guidance, are both arranged with full-time teacher tutoring and online answering questions ${ }^{[3]}$. We build a learning platform to provide students with rich learning resources, but also provide exercises for students to learn independently and test and test the learning effect, so that to make up for the shortcomings. The experimental center provides students with 40 hours of free study time each semester, allowing students to learn independently, to fill gaps, and to consolidate the knowledge learned. After the completion of the study task, according to the specific conditions of the students, students are usually organized to conduct a computer proficiency test every semester. Second, the diversified learning model includes the classroom teaching mode, the teacher guiding model and the teaching resource learning model. Each model has its own characteristics and advantages, which pays attention to improving students' computer ability. In the process of teaching and learning, the students adopt the corresponding learning mode flexibly according to their interests and hobbies, so as to achieve the purpose of improving the learning efficiency, consolidate the knowledge learned and improve the applied skills of computer knowledge. 


\subsection{Construction of Experimental Teaching System}

Experimental teaching is a key content in the whole basic computer teaching. In teaching, we should adhere to the principle of ability cultivation and establish a "modular, multi-level" system. According to the purpose and requirements of the experiment, we should design our own scheme to explore and successfully complete the experiment task. We should be guided by ability development, and appropriately reduce the proportion of demonstration experiments, expand comprehensive and design experiments. Moreover, according to the teaching objectives and requirements, we should let the students design, explore and study independently, effectively complete the task of computer experiment, and enhance the students' ability to solve problems by computer. Specifically, the experimental teaching system consists of three levels, and the first level is the basic skill level, including the computer software and hardware operation and basic principle verification. The second level is the level of comprehensive application and design ability, including comprehensive and design experiments. The third level is innovation ability level, including extracurricular science and technology activities, computer science and technology competition and so on. Perfecting the experimental system is helpful to promote the teaching activities and improve the students' experimental level and computer ability ${ }^{[4]}$.

\subsection{Application of Multiple Teaching Mode}

We should aim at improving students' ability and apply multiple teaching model. In body, the following effective teaching mode can be adopted. First, this mode is used in the teaching of basic computer skills, including the use of computer software and hardware, the application of network knowledge and so on. Usually, when the teacher is explaining the operation, the student can observe the teacher's operation through learning theoretical knowledge, so that to master the operation points, improve the software and hardware facilities and the application skills of network knowledge. Second, task driven teaching is based on teaching contents and talents training objectives of basic computer courses, and teaching contents are set into one or more tasks, so that students can learn, communicate and discuss in group cooperation form, and accomplish tasks successfully. Each task includes basic computer knowledge and skills training, and it will deepen the understanding of basic knowledge and improve computer capabilities through the completion of tasks ${ }^{[5]}$. Third, in the subject research teaching, the students are organized to carry out the subject research and study activities, and each 5 to 7 students are divided into one group to allocate the learning themes for each group. Each group combines the teaching theme and requirement, completes the topic research task, summarizes the learning result, and submits the research report, which is evaluated and summarized by the teacher. In this way, we can deepen the understanding of the teaching subject, master the basic knowledge of computer, and promote the improvement of students' computer ability.

\subsection{Construction of Information Resources and Learning Platform}

We need to build online learning system and online testing system. The system platform includes upload and download of teaching resources, job publishing, online question answering and discussion, online testing module. Through the construction of the platform, the computer-based curriculum teaching resources are integrated to facilitate the interaction between teachers and students. It not only provides students with independent learning and testing environment, but also provides teachers with online teaching and tutoring functions, which plays an important role in student learning and teaching activities. When students enter the platform, they can learn the basic knowledge independently, carry on the machine operation, complete the teaching task, and can also carry on the online test. The autonomous test system has rich function of test and marking, which is trained by students according to their learning needs. The system automatically marks the papers after the test, and gives the correct answers and detailed answers, which is helpful for the students to improve and consolidate their knowledge in time ${ }^{[6]}$. 


\section{Conclusions}

With the continuous improvement of students' computer ability in the whole society, computer majors should not only master the basic knowledge, but also improve their comprehensive skills, and enhance their adaptability to employment. Therefore, in the teaching of the basic course of college computer, we should adhere to the principle of ability cultivation and take effective countermeasures from the aspects of selecting the content of the teaching material, setting up the course, teaching experiment, teaching mode and so on. This can further promote the university basic computer course teaching innovation reform, stimulate the interest and enthusiasm of students, so that they not only have solid theoretical knowledge, but also effectively enhance computer capabilities. This can also enhance the adaptability of employment posts, effectively improve the teaching effect of the basic computer courses and the quality of personnel training.

\section{Acknowledgements}

Foundation project: teaching reform and research project of Bohai University - The Application of Research Teaching Model based on Symbiosis Theory in the Basic Class Teaching of College Computer (BDJG-14-QN-A-004).

\section{References}

[1] Zhou Ying. Research and Practice on Improving Basic Computer Teaching Ability of Higher Vocational Teachers [J]. Contemporary Educational Practice and Teaching Research, 2017, (06):138.

[2] Liao Keshun. The Practice of Basic Computer Teaching Reform in Higher Vocational Education Based on Application ability [J]. Journal of Guangxi University for nationalities (Natural Science Edition): 114-116.

[3] Li Chao. Research on the Cultivation of Thinking Ability in Basic Computer Teaching and Its Practical Research [J]. The Science and Technology wind, 2013, 19:199-200.

[4] Wang Miao. Research on the Cultivation of Thinking Ability in Basic Computer Teaching and Its Practical Research [J]. Science and Technology Information, 2013, (04):34 + 36.

[5] Ji Chaoyang, Zhao Jitao. Discussion on the Basic Education of Public Computer and the Cultivation of Innovation Ability [J]. Education and Occupation: 18:133-135.

[6] Gong Peizeng, Yang Zhiqiang, Gu Chunhua, Xu Andong. The Reform and Practice of the Cultivation of Computer Practice Ability of College Students [J]. University Teaching in China 2008/06:16-18. 